\title{
SIGNIFICANT RITUALS OF KASHMIRI PANDITS: A PERSPECTIVE
}

\section{SIMRAN KAUR \& AMITA WALIA}

Department of Fabric and Apparel Science, Institute of Home Economics, University of Delhi, New Delhi, India

ABSTRACT
The study was done to deeply understand the diversity in traditions, cultures, and customs of Kashmiri Pandits.
The paper gives details of attires worn by Kashmiri Pandits throughout the most important and meaningful ceremonies of
their lives. Kashmir is home to an array of distinct ceremonies and traditions. Mundan, Namakarana, Yagnopavit are
some of the most significant ceremonies after the birth of a child. Pre-wedding ceremonies like engagement, Divgun,
Mehendiraat and the wedding ceremonies and Lagan hold great significance in their culture. Ceremonies related to
death are also performed in their own way. The paper concludes with the various ceremonies in a lifetime of a Kashmiri
Pandit.
KEYWORDS: Yagnopavit, Divgun, Shran sonder, Kahnethar, Tarang \& Lagan

Received: May 11, 2018; Accepted: Jun 01, 2018; Published: Jul 07, 2018; Paper Id.: IJTFTAUG20183

\section{INTRODUCTION}

Various states of India exhibit unique diversity in their traditions, culture, and rituals. They showcase different religions and distinct practices. These rituals are an integral part of the individuality of these states and their cultural practices. Kashmir, as much as it is famed for its beauty, is also celebrated for its people and their unique way of life. The aesthetics and rituals of the people of Kashmir keep them close to their distinctive yet unparalleled traditions. Traditions and culture hold an important place in the lives of every individual. The followers of the Vedic religion, popularly known as the Hindus, consider performing of the Sanskaar to be of the highest merit for developing the human personality for mental health and spiritual awakening.

\section{RITUALS AND CEREMONIES}

\section{Rituals in Pregnancy}

\section{Garbhadhana}

Garbhadhana is a ceremony performed before conception. It is usually performed when the husband and wife decide to have a child and raise a family together. Garbha means womb and Dhana means wealth. It thus, translates to attaining the wealth of womb. It is performed to ensure a happy family life. It is first of the sanskaras performed by the Kashmiri Pandit families.

\section{Pumsavana}

This ceremony is performed to give rise to a male progeny. It is generally performed in the third or fourth month of pregnancy. It is celebrated to fulfill the desire of a male child in the family of Kashmiri Pandits, to help carrying the family forward. 


\section{Simantonnayana}

It is a hair parting ceremony. It involves parting the hair of pregnant women to ward off all evil spirits. It is performed to wish for the safe delivery of the unborn child and to bless the baby with a long life. It is usually performed during the last trimester of pregnancy.

\section{Dod Dyun}

Pregnant women moved to their parent's house around the seventh month from where they would return with gifts, new clothes and pots (matka) of curd, which were regarded as highly auspicious. This ceremony of giving curd is known as Dod Dyun and it is an occasion for rejoicing in Kashmiri Pandit families as a woman's first conception is regarded as the biggest event in her life. This ceremony is celebrated after the first baby, it's voluntary for the second baby and not celebrated after the third baby.

\section{Rituals at Birth}

\section{Shran Sonder}

On the sixth day after the child's birth, both mother and child are bathed. The bath is called the Shran Sonder. This ritual is performed along with havan.

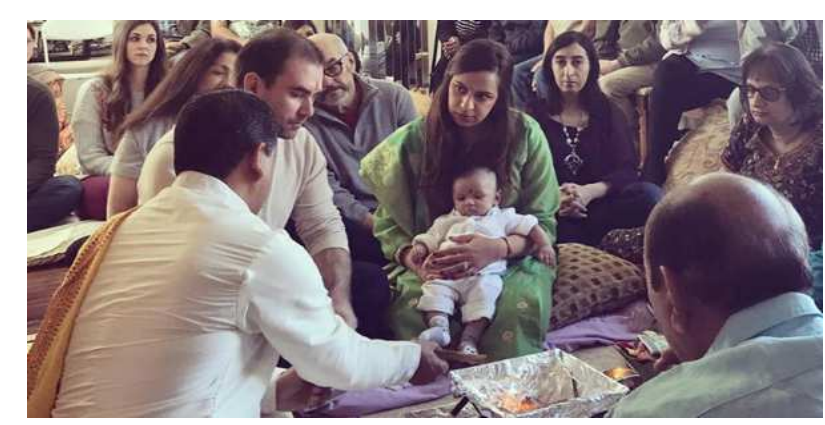

Figure 1: Havan after Shran Sonder Ceremony

\section{Kahnethar}

For eleven days after the birth of a child, the family and near relatives cannot perform any religious ceremonies. On the eleventh day, a purification ceremony called the Kahnethar takes place. In the Kashmiri language, the word kah means eleven and the word nethar means nakshatra. Hence, this ceremony is performed on the eleventh nakshatra from the child's birth. It is performed to grace the child with blessings of the deities and to accept the newborn into the family. The ceremony involves the ritual of feeding the child with a spoonful of ghee and keeping a coin on their tongue. The child is shown their reflection in the water. Only the mother, father, and child take part in the ceremony.

\section{Namakarana}

The ceremony of naming the child is called Namakarana. The child can be named on any auspicious day.

\section{Mundan}

Another auspicious ceremony that takes place after the birth of a newborn is the Mundan of the child. Also called Zarkasaai by the natives of Kashmir, it is the first haircut and is believed to relieve the child of all impurities and purify them. It is also known to ward off evil eye from the newborn. 


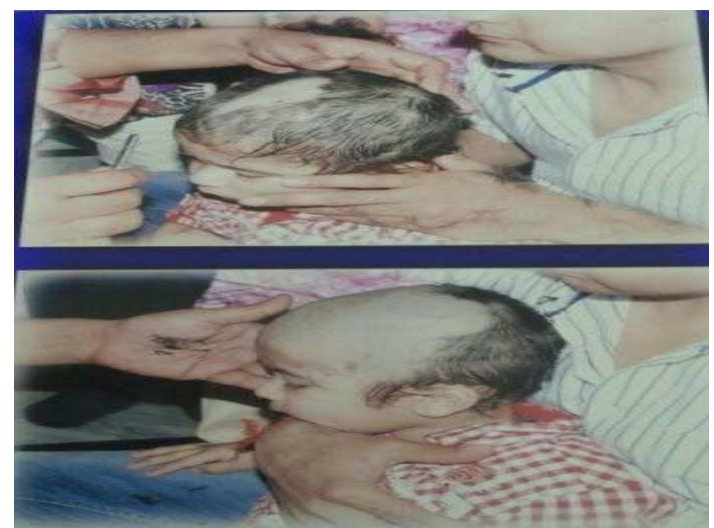

Figure 2: Mundan Ceremony

\section{Yagnopavit}

Also known as Mekhal, it is a sacred thread-ceremony of the male child. It is usually performed during childhood, preferably when the child turns 8 . This sacred thread is extremely significant as it marks the beginning of education for the child. A havan is performed to purify the thread. The thread is then worn by the child. However, if this ceremony could not be performed in the childhood due to any reasons, it is performed a few days before marriage. One reason for not performing this ceremony in childhood could be someone's death in the family. Then, this ritual is not performed until an important event, like the marriage of a sibling or their own marriage takes place. It is one of the most important ceremonies in the life of a Kashmiri Pandit.

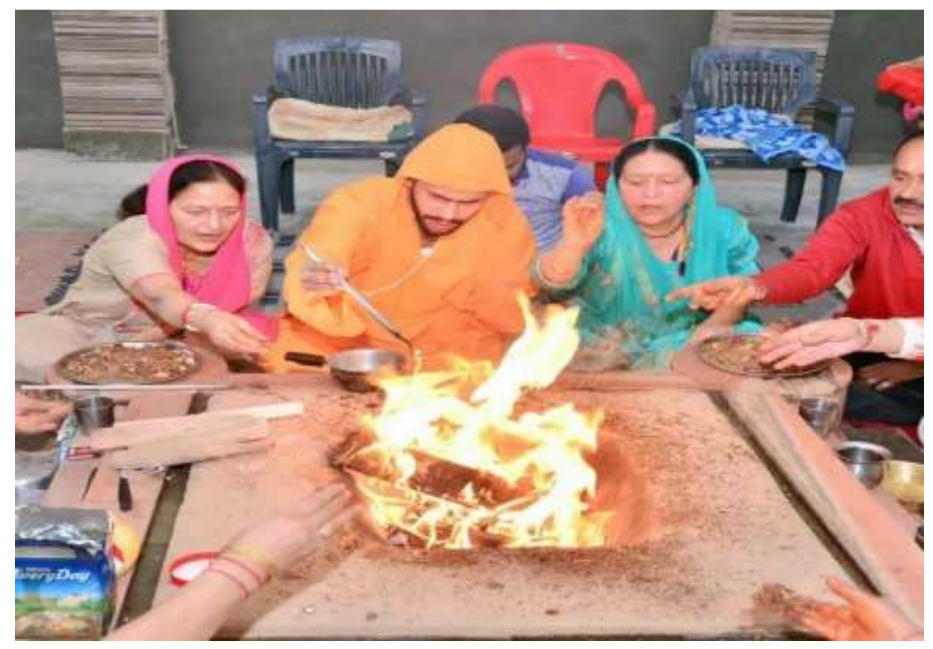

Figure 3: Yagnopavit Havan Being Performed by Kashmiri Pandit Boy

\section{Rituals of Marriage}

\section{Satlivun}

This ceremony involves braiding the hair of the bride-to-be by her maternal aunt. A little mehendi is applied on the hands of the bride-to-be by her maternal aunt as a token of auspiciousness. It marks the beginning of all wedding ceremonies. In earlier times, brides were restricted to step out of the house after this ceremony was performed. It is an informal announcement of the wedding. Invitation cards are distributed only after this ceremony. 


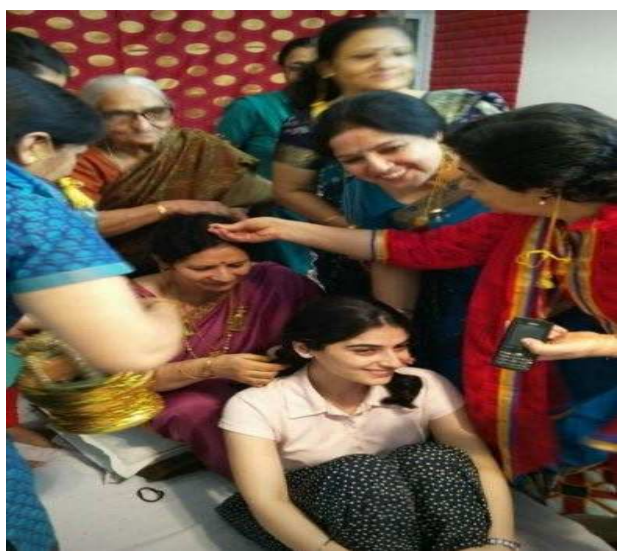

Figure 4: Braiding the Hair

\section{Engagement Ceremony}

It is a pre-wedding ritual in which the boy and girl exchange rings and get betrothed in the presence of both the families. They are blessed by relatives and friends.

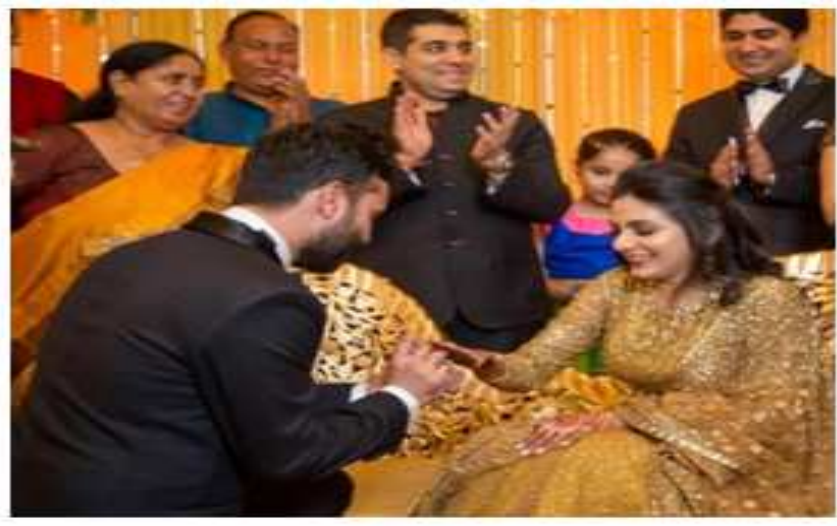

Figure 5: Engagement Ceremony

\section{Maanziraat/ Mehendiraat}

The ceremony of Maanziraat takes place in which the bride/groom takes part in a bathing ritual in the evening after which, her hands and feet are dyed with maanz(henna). Respective paternal aunts wash the bride's \& groom's feet and apply mehendi on their hands and feet. Maanz is also distributed amongst all the female relatives, friends and neighbors. A delicious Kashmiri meal prepared is then served to the guests, post which everyone takes part in a lively wanwun which are the sangeet sessions. A significant instrument, known as tumbaknaer, is usually played in these sangeet sessions. It is made of wood and is typical to Kashmiri weddings. In the groom's house, both mehendi and sangeet sessions take place. The groom's hands are also dyed with a little mehendi as a symbol of auspiciousness. 


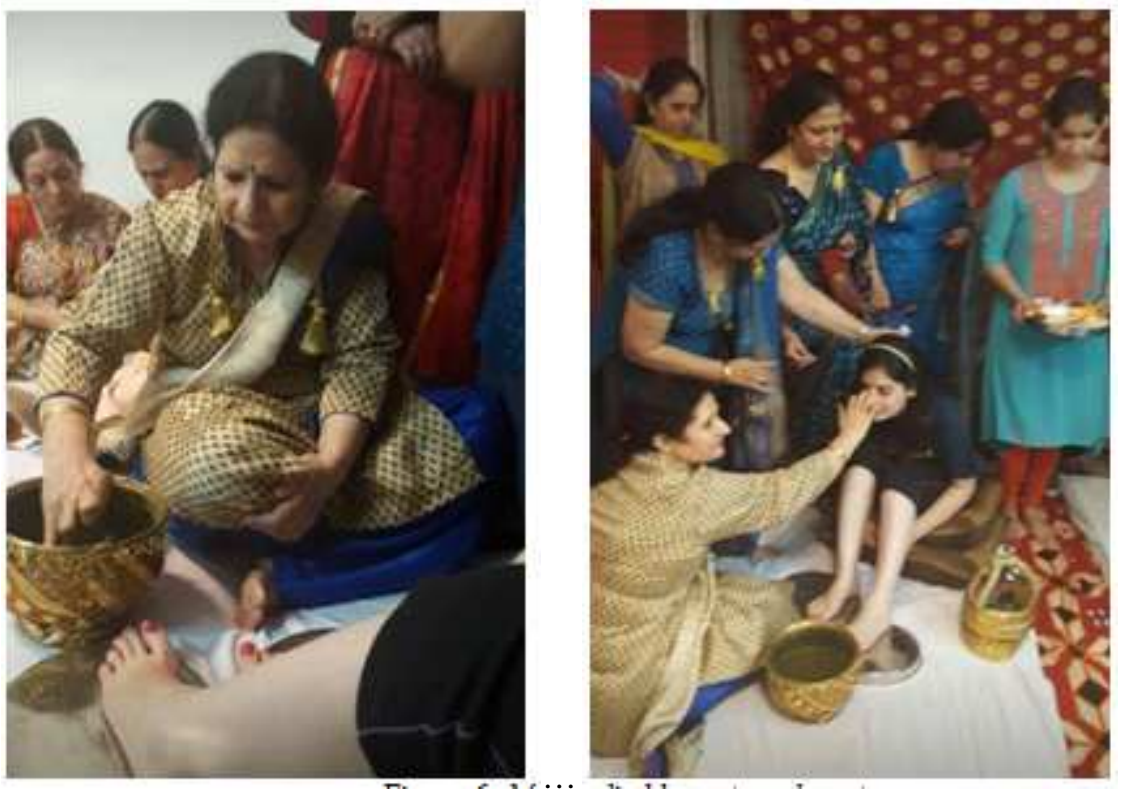

Figure 6: Maanz Applied by Paternal Aunt

\section{Divgun}

It is an auspicious ceremony which is performed at the time of marriage. It involves the ritual of bathing the bride or groom with a mixture of milk, rice, water and curd, known as Kanishran. All family members and relatives are present during this ceremony. A dupatta/cloth is placed above the bride/groom's head before pouring milk. Its significance is to filter the milk before it is poured. The priest chants holy prayers throughout the ceremony. It is a ceremony that marks the transition of the bride and the groom from Brahmacharya Ashram to Grihastha Ashram. It involves performing a havan before and after Kanishran. In this ceremony, the bride wears the traditional ornament dejhoor for the first time. This ear ornament is strung on a sacred thread and is gifted to her by her parents along with clothes and other items of jewellery. Dejhoor or dejaharu is a piece of jewellery cast in gold and is always hexagonal (shatkon) shaped with a dot (chunne) in the center. It is believed to be a yantra denoting Shiv and Shakti. This yantra, Dejhoor, is dangled from piercings in the upper ear cartilage, always the left ear first and then the right, only using a red thread known as nairwan. The significance of wearing the dejaharu is that the bride is now ready for marriage. After marriage, the bride is gifted a golden thread or a golden chain (atah), by her mother-in-law. This golden chain replaces nairwan. This ritual signifies the welcoming of the new bride to her in-laws house. After Kanishran, the bride and groom are showered with flowers at their respective places. They then, change into the attire gifted to them by their maternal uncle. After this, the bride's face is covered to protect her from the evil eye. Her maternal uncle then carries her on his shoulders to the place where havan is being performed. The significance of this ritual is to maintain her purity after the bathing ceremony. Following this, a havan is performed where all the ladies of the family are present. The paternal aunt ties the bride's hair into two loose ponytails which are held by mauli (red thread). The dejhoor is now gifted to the bride by her paternal aunt and the pooja is performed. After this ritual, the bride's parents give her clothes, household items and jewellery. Similarly, at the groom's place, his maternal uncle presents him with new clothes. 


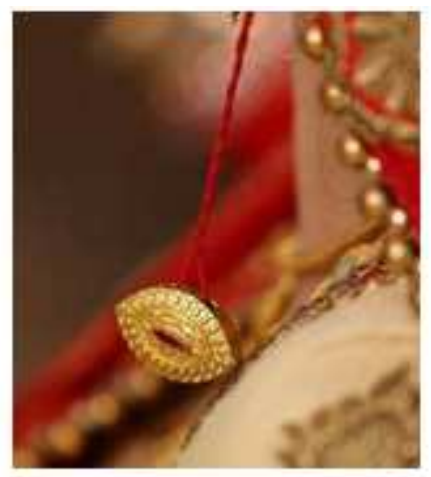

Figure 7: Dejhoor attached to Nairwan

\section{Mas Muchravum}

It is a ceremony in which the maternal aunt of the girl braids her hair into locks tying the headgear (tarang) over it. These locks are opened only after marriage. This ceremony is known as Mas Muchravum. All the ladies in the house sing Kashmiri folk songs

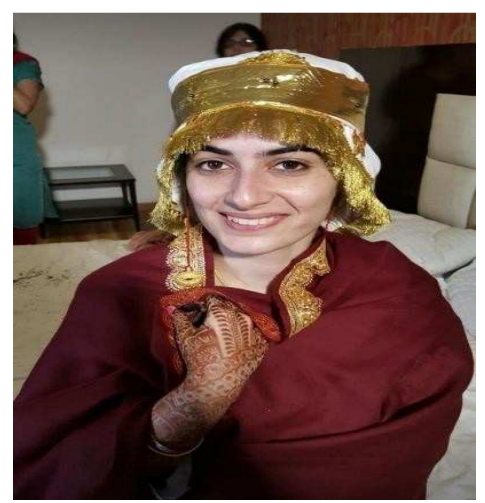

Figure 8: Tarang Tied to Bride's Head

\section{Jaimala}

Also known as Varmala, it is a wedding ceremony performed by Kashmiri Pandits in which the bride and groom exchange flower garlands. This ceremony is a union of two souls and their families.

\section{Wedding Ceremony (Lagan)}

During the lagan ceremony, the holy fire is lit, and the couple chants prayers and perform rituals as directed by the priest. The ritual of Kanyadaan is then performed by the father of the bride. This ritual signifies acceptance by the bride's father as well as his official approval to give his daughter away. The bride and groom are then made to hold hands firmly. After this, their hands are covered with a cloth. This cloth is called athwas. A golden thread called mananmal is then tied to the foreheads of both the bride and the groom by the mother of the bride. The significance of this ritual is that the bride's mother is accepting the groom and the pair is now accepted as a couple. Praying for a strong future ahead, the left foot of both is placed on a kajwat (grinding stone). This is followed by the pheras around the auspicious fire in the middle. The first phera is completed by stepping on seven coins/ rupee notes, by the bride. The bride is viewed as the embodiment of Goddess Lakshmi. After the completion of the seven pheras, the couple seeks blessings from all the elder members of the family and relatives. This wedding ceremony of Kashmiri Pandit is followed by Posh Pooja. 


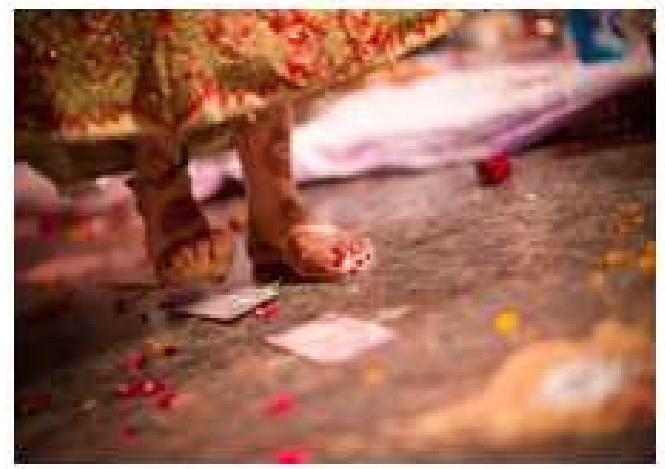

Figure 9: Bride Walking on Rupee Notes

\section{Posh Pooja}

The Posh Pooja is a significant ceremony which observes showers with posh (flowers). In this ceremony, a red cloth is placed on the newlywed couple's heads and everyone showers them with flowers and holy prayers. About $20-30$ $\mathrm{kgs}$ of marigold and rose petals are used for this ceremony as the bride and groom are considered as the embodiment of Lord Shiva and Goddess Parvati. After this ceremony, the bride bids adieu to her family and relatives and leaves with the groom.

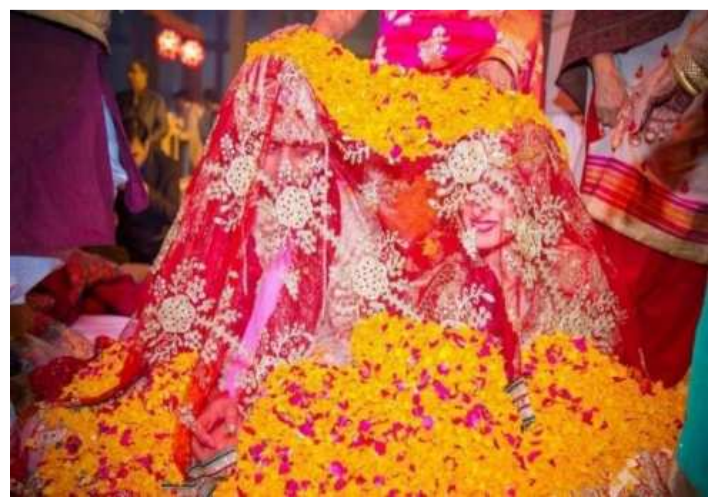

Figure 10: Posh Pooja Ceremony

Vidaai

It is the last ceremony of the wedding day. In this, the bride takes blessings from her family and relatives. She then, bids them goodbye and leaves with the groom and her in-laws, to their home.

\section{Satraat}

After marriage, the bride's first visit with her husband to her parent's home is known as Satraat. The bride's brother goes to bring her home. The parents of the bride gift her new clothes along with salt and cash. When the newlyweds visit the bride's house for the second time, the ceremony is known as Phirlath. The bride and groom are welcomed with a feast.

\section{Rituals at Death}

In Kashmiri Pandit families, the dead body is bathed and wrapped in a white shroud (kafan). A brief Shradha ceremony is performed before the dead body is carried to the cremation ground. Hymns are chanted before putting the dead 
body on the pyre. The funeral pyre is preferably lit by the son of the dead. After the dead body is consumed by the fire, the mourners return. For ten days, Shradha ceremonies are performed for the peace of the departed soul. On the 10th day, the son shaves his head to signify the end of mourning. Shradha ceremony continues up to the 11th and 12th days, and then every month for the first year. After this, yearly Shradhas are performed.

\section{CONCLUSIONS}

- Kashmiris are accustomed to celebrating few rituals during pregnancy. These ceremonies are performed as a good omen, to wish for a safe delivery and to bless the child with a long healthy life. These rituals are the first few sanskaaras performed in Kashmiri Pandit families.

- Rituals at birth: Most of these ceremonies are performed on particular dates according to the rituals and nakshatras.It was however, intriguing to note that if there is a death in the family, no ceremonies are performed for the newborn. Then, these rituals are performed when an auspicious occasion like marriage takes place in the immediate family of the child.

- Rituals at marriage: The rituals for marriage are mostly different for both the communities. Satlivun marks the onset of wedding ceremonies in Kashmiri Pandit families. It is followed by the engagement ceremony, divgun, maanziraat, mas muchravum, lagan, posh pooja, vidaai and satraat.

- Rituals on death: According to the rituals of Kashmiri Pandits, the body of the deceased is bathed and wrapped in a white shroud (kafan). Hymns and prayers are chanted and the dead body is put on the funeral pyre. The pyre is preferably lit by the son of the deceased. The body is cremated and the mourners return. Shradhas are then performed until the 12th day for the peace of the departed soul. After this, the shradha ceremonies are performed yearly.

\section{REFERENCES}

1. Dhar, S., (1986), Jammu and Kashmir Folklore, South AsiaBooks

2. Bamzai, P., (2009), A History of Kashmir, GulshanBooks

3. Saraf, D., (1987), Arts and Crafts, Jammu and Kashmir: Land, People, Culture, AbhinavPublications 